\title{
Surgical Stabilization of Clavicle Fractures Reduces Organ Failure Rates in Multiply-injured Patients with Thoracic Trauma: An Analysis Based on the TraumaRegister DGU®.
}

Helge Eberbach ( $\square$ helge.eberbach@uniklinik-freiburg.de )

University of Freiburg Hospital: Universitatsklinikum Freiburg https://orcid.org/0000-0002-6974-8266

\section{Rolf Lefering}

Universität Witten/Herdecke: Universitat Witten/Herdecke

\section{Sven Hager}

Oberlausitz Hospital Group: Oberlausitz Kliniken gGmbH

\section{Klaus Schumm}

Freiburg University Hospital: Universitatsklinikum Freiburg

\section{Lisa Bode}

Freiburg University Hospital: Universitatsklinikum Freiburg

Martin Jaeger

Freiburg University Hospital: Universitatsklinikum Freiburg

\section{Dirk Maier}

Freiburg University Hospital: Universitatsklinikum Freiburg

Johannes Kalbhenn

Freiburg University Hospital: Universitatsklinikum Freiburg

Thorsten Hammer

Freiburg University Hospital: Universitatsklinikum Freiburg

Hagen Schmal

Freiburg University Hospital: Universitatsklinikum Freiburg

Jörg Bayer

Freiburg University Hospital: Universitatsklinikum Freiburg

\section{Research article}

Keywords: multiple injuries, clavicle fracture, thoracic trauma, lung failure, multiple organ failure

Posted Date: October 14th, 2020

DOI: https://doi.org/10.21203/rs.3.rs-89466/v1 
License: (c) (i) This work is licensed under a Creative Commons Attribution 4.0 International License. Read Full License 


\section{Abstract}

Introduction: Thoracic trauma has decisive influence on the outcome of multiply-injured patients and is often associated with clavicle fractures. The affected patients are prone to lung dysfunction and multiple organ failure. The aim of this study is to investigate the influence of surgical stabilization of clavicle fractures in patients with thoracic trauma on specific outcome parameters.

Methods: A multi-center, retrospective analysis of patient records documented in the TraumaRegister DGUß between 2009 and 2015 was performed. The inclusion criteria were multiply-injured patients with thoracic trauma and associated clavicle fracture, maximum AIS severity $\geq 3$ and admission to the intensive care unit. The influence of operative vs. non-operative clavicular fracture treatment and timing of surgery on lung failure, multiple organ failure, sepsis, length of ICU stay, intubation time and length of hospital stay was assessed by regression analysis.

Results: A total of 3,209 patients were included in the analysis. In 1,362 patients (42\%) the clavicle fracture was treated operatively after $7.1 \pm 5.3$ days. Surgically treated patients had a significant reduction in lung failure $(p=0.013, O R=0.74)$, multiple organ failure $(p=0.001, O R=0.64)$, intubation time ( $p=0.004 ;-1.81$ days $)$ and length of hospital stay $(p=0.014 ;-1.51$ days $)$ compared to non-operative treatment. Moreover, surgical fixation of the clavicle within five days following hospital admission significantly reduced the rates of lung failure $(p=0.01, O R=0.62)$, multiple organ failure $(p=0.01, O R=$ $0.59)$ and length of hospital stay ( $p=0.01 ;-2.1$ days).

Conclusions: Based on our results, multiply-injured patients with thoracic trauma and concomitant clavicle fracture seem to benefit significantly from surgical stabilization of a clavicle fracture, especially when surgery is performed within the first five days after hospital admission.

\section{Introduction}

More than $50 \%$ of all multiply-injured patients with an injury severity score $\geq 16$ suffer from thoracic trauma [1, 2]. Early detection of life-threatening injuries and administration of optimal emergency care (e.g. chest tube, intubation, fluid administration) are essential to achieve the best possible outcome [3, 4]. However, late or inadequate treatment of thoracic trauma increases the risk of developing severe complications such as respiratory failure, ARDS, long-term morbidity, and higher mortality rates [3,5-7].

A reliable indicator for underlying thoracic injuries is a clavicle fracture which is easily diagnosed during the primary survey in early trauma patient care [8]. In multiply-injured patients sustaining a clavicle fracture concomitant thoracic injuries occur in $77 \%$ [9]. Therefore, the clavicle can be considered the gatekeeper of the thorax $[10,11]$.

Despite advances in ventilatory management like lung-protective, non-invasive ventilation protocols, patients with thoracic trauma often require prolonged ventilatory support and protracted ICU and hospital stays [12-14]. Since clavicular injuries represent a severe loss of integrity of the chest and upper quarter 
of the body, disorders in breathing mechanics can occur [15]. This might be attributed to either direct functional deficiency or as a consequence of associated pain [15], especially since the breathing mechanism doesn't only consist of the chest wall itself and the diaphragm. An intact and stable clavicle, as the origin of the accessory inspiratory muscles, is a crucial prerequisite for effective respiration and oxygenation $[16,17]$.

Therefore, the purpose of this study was to investigate the influence of surgical stabilization of clavicular fractures in multiply-injured patients with thoracic trauma on lung failure, multiple organ failure, sepsis rate, intubation time, length of intensive care unit stay and length of hospital stay. We hypothesized that osteosynthesis of the clavicle is associated with reduced complication rates and has an influence on ICU and hospital stay.

\section{Methods}

\section{The TraumaRegister DGU®}

The TraumaRegister DGU® (TR-DGU) of the German Trauma Society (DGU) was founded in 1993. The aim of this multicenter database is the anonymized and standardized documentation of severely injured patients.

Data are collected prospectively in four consecutive time periods from the accident site until hospital discharge: (A) pre-hospital phase, (B) emergency room and initial surgery, (C) ICU, and (D) discharge. The documentation includes detailed information on demographics, injury patterns, comorbidities, pre- and inhospital management, course in the ICU, relevant laboratory findings including each individual's data on transfusions, and outcome.

The inclusion criterion is admission to the hospital via the emergency room with subsequent ICU care or reaching the hospital with vital signs and dying before admission to the ICU.

The infrastructure for documentation, data management, and data analysis is provided by the Academy for Trauma Surgery (AUC), a company affiliated with the German Trauma Society.

Scientific leadership is provided by the Committee on Emergency Medicine, Intensive Care and Trauma Management (Section NIS) of the German Trauma Society. The participating hospitals submit their anonymized data into a central database via a web-based application. The quality of the scientific data analysis is monitored by peer review procedure established by Section NIS.

The participating hospitals are primarily located in Germany (90\%), but a rising number of hospitals in other countries are contributing data as well (currently from Austria, Belgium, China, Finland, Luxemburg, Slovenia, Switzerland, The Netherlands, and the United Arab Emirates). Approximately 35,000 cases from more than 700 hospitals have been entered into the database per year. 
Participation in TR-DGU is voluntary. For hospitals associated with TraumaNetzwerk DGU®, however, the entry of at least a basic data set is obligatory for reasons of quality assurance. Hospitals interested in trauma research must enter a standard data collection form that contains more comprehensive information (e.g., organ failure, sepsis) on the patient course compared with the basic data set.

\section{Patients}

Patients documented between 2009 and 2015 in the TR-DGU® were analyzed for eligibility in this investigation. Patient selection based on the following criteria: (1) standard documentation (including surgery and organ failure assessment) from German trauma centers, (2) diagnosed clavicle fracture with documentation of treatment modality (3) maximum AIS severity $\geq 3$ and (4) requirement of initial intensive care.

Patients with relevant head injury, defined as AIS $_{\text {Head }} 4-6$, were excluded since serious head trauma may pose an indication for intubation and prolonged mechanical ventilation itself [18]. Also, patients admitted more than 24 hours after trauma to a referring hospital and patients transferred into another institution within 2 days after hospital admission were excluded to prevent confounding. Finally, patients who died within 24 hours were excluded from analysis since the surgical treatment of their clavicle fracture was deemed unlikely (Fig. 1).

Patients included in the final analysis were divided into two subgroups (operative versus non-operative treatment) according to the clavicle fracture treatment. The operative therapy group comprises all stabilization methods performed (e.g. plate osteosynthesis, elastic stable intramedullary nailing, etc.).

We performed an additional subgroup analysis of patients undergoing surgical clavicular stabilization regarding the timing of surgery to evaluate the impact of early operation. Therefore, we defined the time frame for early clavicular surgery to be performed within 5 days after trauma.

Injuries were graded according to the 2008 version of the Abbreviated Injury Scale (AIS) [19], and the injury severity score (ISS) [20] was calculated as described. The ISS is calculated from the three worst affected body regions as the sum of squares of the respective AIS severity levels [21].

Lung failure was assessed by the sepsis-related organ failure assessment (SOFA) score. The SOFA score describes organ function in the respiratory, cardiovascular, renal, hematologic, hepatic, and central nervous systems [22]. Each organ system was graded to evaluate the severity of organ dysfunction or failure. Patients with organ failure entered in the TR-DGU database had to have met the SOFA score criteria for organ failure ( 3 or 4 points per organ) for at least 2 days.

Multiple organ failure (MOF) and sepsis were assessed according to published guidelines [23]. Sepsis was defined as a systemic response to infection (proven presence of microorganisms). Data on respiratory failure, MOF, and sepsis were only available from patients documented with the standard data collection form. 
Length of intensive care unit stay was defined as days spent in the intensive care unit and length of mechanical ventilation was defined as the number of days spent in the ICU with endotracheal intubation or tracheostomy and mandatory mechanical ventilation (e.g. excluding non-invasive ventilation). Length of hospital stay was defined as the time spent in the hospital.

The Revised Injury Severity Classification II Score (RISC II) [24] was calculated for outcome adjustment. The model consists of the following predictors: worst and second-worst injury (AIS severity level), head injury, age, sex, mechanism, pupil reactivity and size, pre-injury health status, blood pressure, acidosis (base deficit), coagulation, hemoglobin, and cardiopulmonary resuscitation [24].

\section{Statistical Analysis}

Demographic and clinical characteristics comparing two treatment groups were evaluated using descriptive statistics. Continuous variables are presented as mean with standard deviation (SD), while categorical variables are presented as number of cases with percentages. The respective statistics refer to patients with valid data sets only. Data of lung failure, MOF and sepsis are not part of the basic data set. Therefore, the total number of patients or characteristics may vary.

Statistical testing for the effect of operative treatment on the outcome was performed using multivariate logistic or linear regression analysis. In this analysis, the dependent variables were lung failure, MOF, sepsis, length of ICU stay, length of mechanical ventilation and length of hospital stay, respectively. The independent variables consisted of patient characteristics (age, sex), injury severity (ISS, AIS Head, $_{\text {, }}$

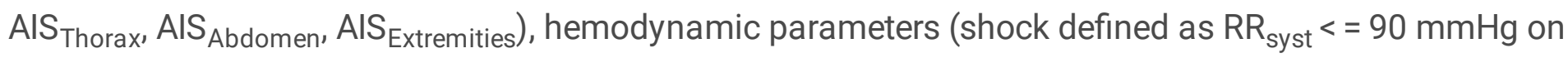
admission) and therapeutic interventions (intubation, blood transfusion).

A subgroup-analysis was performed to assess the impact of early operative treatment within five days after trauma compared to late operative treatment.

The level of significance was set at $p<0.05$. All data were analyzed using SPSS, version 26.0 (IBM Corp. in New York, USA).

\section{Results}

\section{Basic characteristics of all included patients}

The initial database contained 145,518 patients. After applying inclusion and exclusion criteria a total of 3,209 multiply-injured patients with thoracic trauma and concomitant clavicle fracture remained for analysis (Fig. 1).

The included patients were predominantly male (73.5\%), had a mean age of $49.0 \pm 19.3$ years and a mean ISS of $22.9 \pm 8.8$. In 1,362 patients $(42.0 \%)$ the clavicular fracture was treated operatively after 7.1 \pm 5.3 days. $19,1 \%$ had an $\mathrm{AIS}_{\text {Thorax }}<3$ and $80.9 \%$ an $\mathrm{AlS}_{\text {Thorax }} \geq 3$. The overall mortality rate was $3.7 \%$; 
$6.1 \%$ of patients deceased in the non-operative group compared to $0.6 \%$ in the operative group. Further study group's characteristics are summarized in Table 1.

Table 1

Basic characteristics

\begin{tabular}{|c|c|c|c|c|c|c|}
\hline & $\mathrm{n}$ & $\operatorname{Sex}(f / m)$ & Age (y) & ISS & $\begin{array}{l}\text { Number of } \\
\text { injuries ( } n \text { ) }\end{array}$ & Mortality \\
\hline $\begin{array}{l}\text { Non-operative } \\
\text { treatment }\end{array}$ & $\begin{array}{l}1847 \\
(57.6 \%)\end{array}$ & $28.4 / 71.6 \%$ & $\begin{array}{l}51.3 \pm \\
20.8\end{array}$ & $\begin{array}{l}22.6 \pm \\
9.1\end{array}$ & $6.8 \pm 3.0$ & $6.1 \%$ \\
\hline $\begin{array}{l}\text { Operative } \\
\text { treatment }\end{array}$ & $\begin{array}{l}1362 \\
(42.4 \%)\end{array}$ & $24.0 / 76.0 \%$ & $\begin{array}{l}45.9 \pm \\
16.6\end{array}$ & $\begin{array}{l}21.3 \pm \\
8.3\end{array}$ & $6.4 \pm 2.8$ & $0.6 \%$ \\
\hline Total & $\begin{array}{l}3209 \\
(100 \%)\end{array}$ & $26.5 / 73.5 \%$ & $\begin{array}{l}49.0 \pm \\
19.3\end{array}$ & $\begin{array}{l}22.0 \pm \\
8.8\end{array}$ & $6.6 \pm 2.9$ & $3.7 \%$ \\
\hline Significance & & $0.005^{\star}$ & <. $001 *$ & <. $001 *$ & $0.001 *$ & $<0.001^{*}$ \\
\hline
\end{tabular}

The majority of patients sustained their injuries during road traffic accidents, mainly riding motorcycles $(26.9 \%)$ and cars $(24.2 \%)$. Figure 2 illustrates all accident causes.

Most patients (83.2\%) were treated at a supra-regional level I trauma center, $15.1 \%$ at a regional level II center and $1.7 \%$ at a local level III trauma center.

In level I and II centers patients received non-operative treatment in the majority of cases $(57.9 \%$ and $57.3 \%$, respectively), whereas in level III trauma centers operative therapy was chosen more frequently (55.6\%), as shown in Fig. 3.

Overall, non-operative therapy was preferred especially in patients under 20 and over 60 years of age (Fig. 4).

$19.3 \%$ of finally analyzed patients suffered from subsequent lung failure, $19.7 \%$ from multiple organ failure and $6.4 \%$ sustained sepsis. For all included patients, mean time spent on ICU was $9.4 \pm 11.7$ days, mean intubation time $7.4 \pm 11.4$ days and mean hospital stay $22.4 \pm 18.0$ days.

Patients with operative treated clavicle fractures also seemed to have lower rates of lung, multiple organ failure and sepsis and spent less time intubated in ICU as well as in hospital (Table 2). 
Table 2

Outcome parameters

\begin{tabular}{|lcccccc|}
\hline & LF & MOF & Sepsis & ICU (d) & $\begin{array}{l}\text { Intubation } \\
\text { (d) }\end{array}$ & $\begin{array}{l}\text { Hospitalization } \\
\text { (d) }\end{array}$ \\
\hline $\begin{array}{l}\text { Non-operative } \\
\text { treatment }\end{array}$ & $23.1 \%$ & $24.8 \%$ & $7.3 \%$ & $\begin{array}{l}10.5 \pm \\
12.4\end{array}$ & $8.7 \pm 12.0$ & $22.6 \pm 18.1$ \\
\hline $\begin{array}{l}\text { Operative treatment } \\
\text { Total }\end{array}$ & $14.1 \%$ & $12.9 \%$ & $5.1 \%$ & $7.9 \pm 10.4$ & $5.3 \pm 10.4$ & $22.0 \pm 17.9$ \\
\hline LF, lung failure; MOF, multiple organ failure; ICU, intensive care unit. & & \\
\hline
\end{tabular}

Whether these differences were statistically significant and attributable to operative treatment we sought to examine with the following logistic regression analysis.

\section{Influence of operative treatment on outcome parameters}

In the regression analysis surgically treated patients showed significantly reduced rates of lung failure ( $p$ $=0.013, \mathrm{OR}=0.74,[0.58-0,94])$ and multiple organ failure $(p=0.001, \mathrm{OR}=0.64,[0.50-0,83])$.

While no significant effect was found on sepsis rates and time on ICU, operatively treated patients had significant less intubation time ( $p=0.004 ;-1.8$ days) and less total days in hospital $(p=0.014 ;-1.5$ days $)$ compared to non-operatively treated patients (Table 3 ).

Table 3

Influence of operative treatment on outcome parameters

\begin{tabular}{|c|c|c|c|c|c|c|}
\hline & LF & MOF & Sepsis & $\begin{array}{l}\text { ICU } \\
\text { (d) }\end{array}$ & $\begin{array}{l}\text { Intubation } \\
\text { (d) }\end{array}$ & $\begin{array}{l}\text { Hospitalization } \\
\text { (d) }\end{array}$ \\
\hline $\begin{array}{l}\text { Regression } \\
\text { coefficient }\end{array}$ & -0.23 & -0.44 & -0.08 & -0.53 & -1.81 & -1.51 \\
\hline $\begin{array}{l}\text { Odds ratio [95\% } \\
\text { Cl] }\end{array}$ & $\begin{array}{l}0.74 \\
{[0.58-} \\
0.94]\end{array}$ & $\begin{array}{l}0.64 \\
{[0.50-} \\
0.83]\end{array}$ & $\begin{array}{l}0.92[0.63- \\
1.33]^{[}\end{array}$ & - & - & - \\
\hline Significance & $0.013^{*}$ & $0.001 *$ & 0.669 & 0.182 & $0.004^{*}$ & $0.014^{\star}$ \\
\hline
\end{tabular}

\section{Influence of early operative treatment ( $\leq 5$ days) on outcome parameters}

To assess a possible effect of early operative intervention within the first 5 days after hospital admission within the subgroup of 620 surgically treated patients, we performed an additional logistic regression analysis. 
When considering the operatively treated patients only, early surgical fixation of the clavicle within the first five days led to significant reduction of lung failure $(p=0.01, O R=0.62,[0.44-0,88])$ multiple organ failure $(p=0.01, O R=0.59,[0.41-0,86])$ and total days spent in hospital $(p=0.01 ;-2.1$ days) (Table 4) compared to operative treatment after five days.

Table 4

Influence of early operative treatment ( $\leq 5$ days) on outcome parameters

\begin{tabular}{|c|c|c|c|c|}
\hline & LF & MOF & Intubation (d) & Hospitalization (d) \\
\hline Regression coefficient & -0.47 & -0.53 & -1.84 & -2.10 \\
\hline Odds ratio [95\% Cl] & $0.62[0.44-0,88]$ & $0.59[0.41-0,86]$ & - & - \\
\hline Significance & $0.008^{*}$ & $0.006^{*}$ & 0.534 & $0.007^{*}$ \\
\hline \multicolumn{5}{|c|}{$\begin{array}{l}\text { LF, lung failure; MOF, multiple organ failure. Regression model includes: Age, Sex, ISS, } \text { AIS }_{\text {Head, }} \\
\text { AIS }_{\text {Thorax, }} \text { AIS }_{\text {Abdomen, }} \text { AIS }_{\text {Extremities }} \text { Shock }(<90 \mathrm{mmHg}) \text { in the trauma room, Blood Transfusion, } \\
\text { Intubation. }\end{array}$} \\
\hline
\end{tabular}

\section{Discussion}

The most important finding of our present retrospective study evaluating 3,209 multiply-injured patients is that operative stabilization of concomitant clavicle fractures in patients with thoracic trauma has decisive positive effects on clinically relevant outcome parameters.

In addition to the serious, life-threatening thoracic organ injuries, the bony chest wall is at great risk in multiply-injured patients [25]. Affection of the clavicle is the third most common fracture in multiplyinjured patients $(10.4 \%)$, only surpassed by femoral (16.5\%) and tibial (12.6\%) fractures [26]. Regarding all multiply-injured patients with bony injuries to the chest wall, an additional clavicular fracture is present in even $18.8 \%$ of the cases [27]. Thus, clavicle fractures are common injuries in patients suffering from thoracic trauma.

Basic characteristics of our study cohort correspond to other studies describing the epidemiology of clavicle fractures in thoracic trauma, like the Dutch National Trauma Database [11] or a British collective from Leeds [28]. In these populations patients were also predominantly male and had a mean age of 39.1 and 47.5 years, respectively. While our reported mean age of 49.0 years is slightly higher, their reported ISS was higher with 28.7 and 29.2, compared to our mean ISS of 22.9 [11, 28].

Similar to previously published data on thoracic trauma, motorcycle crashes could be identified as the most frequent injury mechanism for developing a severe thoracic trauma with a clavicle fracture $[11,14$, $29,30]$.

One concern in most studies dealing with multiply-injured patients suffering from thoracic trauma is the heterogeneous patient collective regarding the leading injury and the immanent implication on the 
intensive care course (e.g. periods of mechanical ventilation in severe head trauma). By deliberately excluding more than moderate brain injuries in our patient collective, we sought to limit this risk of bias.

It has been suggested that patients sustaining serious trauma to the chest and suffering from three or more rib fractures should be transferred to a high-volume level 1 trauma center [31, 32]. In line with this recommendation, our patients were treated mainly at level 1 and level 2 trauma centers (98.3\%).

In $42.0 \%$ of cases the clavicular fracture was treated operatively. A study with older data reviewing the years 2002-2013 in the TraumaRegister DGU® described an even higher rate of $52.4 \%$ operative treatments [33], which might be due to more generous inclusion criteria, as all patients with an ISS $\geq 16$ were included.

Our reported patients suffering from thoracic trauma and clavicle fracture showed a prolonged period of ICU stay (mean 9.4 days) and intubation time (mean 7.4 days) compared to published multiply-injured patients without thoracic trauma (ICU: 8.1 days, intubation time: 3.9 days) [3]. Yet, our findings are comparable with previously published data on patients with thoracic trauma (ICU: 11 days, intubation time: 7 days [34]; ICU: 12 days, intubation time: 7 days [14]).

In expert opinions and small case series, several authors recommend surgical stabilization of clavicular fractures in thoracic trauma, particularly in the case of displaced fractures and associated serial rib fractures or flail chest injuries [10,35]. However, to the best of our knowledge, the implication of surgical management of clavicle fractures in thoracic trauma on clinical outcome parameters had yet to be evaluated. This is therefore the first study addressing the impact of operative treatment of the clavicle fracture in patients with relevant thoracic trauma on outcome parameters in a large collective. There are various theoretical reasons supporting surgical stabilization in this subgroup.

In patients with high-energy mechanism of injury clavicle fractures are prone to fracture displacement, also when initial imaging shows nondisplacement [36, 37].

Since the clavicle acts as a stabilizer of the upper quadrant of the chest fracture displacement is causing pain, especially in patients with concomitant ipsilateral rib fractures. The skeleton of the shoulder and chest loses stability and can lead to a loss of function of the shoulder and a pronounced deformation of the chest wall [10].

In particular, the breathing mechanism is affected. A fractured and instable clavicle as the origin of the accessory inspiratory muscles (M. sternocleidomastoideus, Mm. scaleni, M. pectoralis) can cause an ineffective respiration and oxygenation $[16,17]$.

In combination with a severe thoracic trauma it can thereby further the development of multiple organ dysfunction and pulmonary failure [38,39]. Furthermore, it is well known that $80 \%$ of patients with multiple organ failure start with lung failure [28], and that severe thoracic trauma is an independent risk factor for developing multiple organ failure [40, 41], 
To support the thesis that surgical fixation of fractures to the thoracic wall (or origins of inspiratory muscles) can support patient recovery in thoracic trauma several studies of rib fracture fixation have been published. Concerning flail chest injuries there is valid data supporting operative care of the injury to stabilize the thoracic aperture. Flail chest occurs when three or more adjacent ribs are fractured in at least two places, creating a chest wall segment that moves paradoxically from the chest wall [42], The operative treatment of flail chest injuries shows a clear advantage with regard to the clinical course and outcomes in polytrauma $[13,42]$. According to the metaanalysis of Leinicke et al. patients with early stabilization have less intubation time and both the length of stay in the intensive care unit and the total length of stay in the hospital could be significantly reduced by surgical therapy [13].

In our present study we are the first to demonstrate similar results concerning surgical stabilization of clavicle fractures.

$80.9 \%$ of our patients suffered from at least serious thoracic trauma (AIS Thorax $\geq 3$ ). Therefore, to analyze the effect of operative treatment of the clavicle fracture for all thoracic trauma patients the independent variable $\mathrm{AIS}_{\text {Thorax }}$ was included into to the regression model. We also included other possible confounders (age, sex, ISS, AlS Head AIS Thorax, $\mathrm{AlS}_{\mathrm{Abdomen}}, \mathrm{AlS}_{\text {Extremities, }}$ shock $\mathrm{RR}_{\text {syst }}<90 \mathrm{mmHg}$ intubation and blood transfusion) as independent variables into the regression model, and therefore sought to control for confounding.

Surgically treated patients showed a significantly reduced intubation time and length of hospital stay compared to conservative care. Furthermore, the risk of lung failure and multiple organ failure was significantly reduced. Mortality was eminently lower in the operative subgroup. Nevertheless, the reduction in mortality in our data should not be overestimated, because combinations of injuries or comorbidities with a clinically relevant likelihood of mortality can be a reason for not undergoing surgery and therefore pose a bias towards higher mortality in the conservatively treated subgroup.

In our study, the influence of surgical clavicle stabilization on sepsis and length of ICU-stay was not statistically significant. One reason for that finding could be that these variables might be eminently influenced by other major injuries besides the thoracic trauma.

According to our results, operative management of clavicle fractures in thoracic trauma might therefore be a promising treatment strategy that improves patient's outcome, and also lower treatment costs due to less complications and total days in hospital. Yet, these positive results come with the cost of an operative intervention.

But, complications of surgical treatment of clavicle fractures are rare. In a retrospective review of 1,350 clavicular internal fixations, by plate or intramedullary fixation, Leroux et al. reported neurovascular complications to be exceptional, with only 5 neurologic and 5 vascular complications: i.e., < $1 \%$ [43]. A systematic review of Rehn et al. found a prevalence of complications that required additional major surgery of $3.3 \%$ in the operative groups compared to $8.6 \%$ in the non-operative groups [44]. 
As shown in other studies surgical timing and early operative treatment may result in positive implications for the intensive care unit stay and clinical outcome $[45,46]$. In line with studies showing benefits in organ failure reduction and shortening of intubation periods after early operative treatment of fractures in different body regions we are the first to describe this effect in early stabilization of clavicle fractures in thoracic trauma patients.

\section{Limitations}

This study is limited by the nature of a registry study. Hospitals participating in the TR-DGUß are regularly audited, and sample tests are taken to ensure data quality. However, the validity of their documentation is not verified by external monitors as in prospective trials [47].

We excluded patients with more than moderate head injury (AIS $\geq 3$ ) in our study to minimize confounding and, as a result, our findings cannot be readily transferred to severely injured patients sustaining additional major trauma to this body region. We are not able to comment on the performed surgical procedures (e.g. plate osteosynthesis, elastic stable intramedullary nailing, etc.) and treatment protocols, since this information is not available in the TR-DGUß database.

Additionally, we are unable to comment on the fracture morphology, displacement and fractured part of the clavicle, since this information is not available in the TR-DGU® database, either. Therefore, we were unable to include this information in our statistical regression model.

There is an ongoing discussion on the management of multiply-injured patients and timing of osteosynthesis [45]. For small bone fractures no recommendations or studies exist on when to surgically stabilize these injuries in multiply injured patients. For long bone and spinal fractures research exists and some favor stabilization within 72 hours after hospital admission $[45,46]$. Since long bone and spinal fractures are more relevant to patient management on the ICU and are preferably stabilized before small bone fractures, we concluded to examine the time for early clavicular stabilization until 5 days after hospital admission. Although, as mentioned above, this timing is chosen in lack of scientific evidence we based our decision on reasonable clinical experience.

Besides the above stated limitations, to the best of our knowledge, we are the first study group to present comprehensive data on clavicle surgery and timing in multiply- injured patients suffering from concomitant thoracic trauma.

\section{Conclusions}

Based on our data, surgical stabilization of clavicle fractures in multiply-injured patients with thoracic trauma appears to be beneficial and significantly reduces lung and multiple organ failure rates as well as time of invasive ventilation and length of hospital stay. The effect of reduced lung und multiple organ failure rates, as well as shorter hospital stay, was significantly associated with the clavicle stabilization 
being performed within 5 days of hospital admission. Further studies regarding patient-tailored surgery are warranted to elucidate which multiply-injured patients profit from clavicular stabilization.

\section{Abbreviations}

AIS, abbreviated injury scale; ARDS, acute respiratory distress syndrome; ICU, intensive care unit; ISS, injury severity score; MOF, multiple organ failure; LF, lung failure; OR, Odds Ratio; RISC, Revised Injury Severity Classification; $\mathrm{RR}_{\text {syst }}$ systolic blood pressure; SD, standard deviation; SOFA, Sepsis-related organ failure assessment; TR-DGU®, TraumaRegister DGU®

\section{Declarations}

\section{Ethics approval and consent to participate}

The present study is in line with the publication guidelines of the TR-DGU® and registered as TR-DGU® project ID 2017-006. The study was approved by the University of Freiburg Ethics Committee (EK 167/20) and informed consent was waived.

\section{Consent for publication}

Not applicable.

\section{Availability of data and materials}

The datasets used and/or analyzed during the current study are available from the corresponding author on reasonable request.

\section{Competing interests}

None declared.

\section{Funding}

None declared.

\section{Authors' contributions}

JB and HE conceived the study, participated in its design and coordination and drafted the manuscript. RL had full access to all the data in the study and take responsibility for the integrity and the accuracy of 
the data analysis. KS helped to draft the manuscript. JB, HE, SH, and KS collected the data for the study. HS helped in the analysis and interpretation of the data and critically revised the manuscript for important intellectual content. LB, MJ, DM, JK and TH critically revised the manuscript for important intellectual content. All authors read and approved the final manuscript.

\section{Acknowledgements}

None.

\section{References}

1. Vécsei V, Arbes S, Aldrian S, Nau T. Chest Injuries in Polytrauma. Eur. J. Trauma. 2005;31:239-43.

2. Timm A, Maegele M, Lefering R, Wendt K, Wyen H, TraumaRegister DGU. Pre-hospital rescue times and actions in severe trauma. A comparison between two trauma systems: Germany and the Netherlands. Injury. 2014;45 Suppl 3:S43-52.

3. Bayer J, Lefering R, Reinhardt S, Kühle J, Zwingmann J, Südkamp NP, et al. Thoracic trauma severity contributes to differences in intensive care therapy and mortality of severely injured patients: analysis based on the TraumaRegister DGU®. World J Emerg Surg. 2017;12:43.

4. Huber-Wagner S, Lefering R, Qvick M, Kay MV, Paffrath T, Mutschler W, et al. Outcome in 757 severely injured patients with traumatic cardiorespiratory arrest. Resuscitation. 2007;75:276-85.

5. Treggiari MM, Hudson LD, Martin DP, Weiss NS, Caldwell E, Rubenfeld G. Effect of acute lung injury and acute respiratory distress syndrome on outcome in critically ill trauma patients. Crit. Care Med. 2004;32:327-31.

6. Geiger EV, Lustenberger T, Wutzler S, Lefering R, Lehnert M, Walcher F, et al. Predictors of pulmonary failure following severe trauma: a trauma registry-based analysis. Scand J Trauma Resusc Emerg Med. 2013;21:34.

7. Coppola S, Chiumello D. Thoracic trauma and acute respiratory distress syndrome: mind the link! Minerva Anestesiol. 2017;83:1004-6.

8. Horst K, Hildebrand F, Kobbe P, Pfeifer R, Lichte P, Andruszkow H, et al. Detecting severe injuries of the upper body in multiple trauma patients. J. Surg. Res. 2015;199:629-34.

9. van Laarhoven JJ, Ferree S, Houwert RM, Hietbrink F, Verleisdonk EM, Leenen LP. Demographics of the injury pattern in severely injured patients with an associated clavicle fracture: a retrospective observational cohort study. World J Emerg Surg. World Journal of Emergency Surgery; 2013;8:1-1.

10. Langenbach A, Krinner S, Hennig FF, Ekkernkamp A, Schulz-Drost S. Injuries of the posterior and lateral chest wall-importance of an additional clavicular fracture. Unfallchirurg. 2nd ed. 2018;121:615-23.

11. van Laarhoven JJEM, Hietbrink F, Ferree S, Gunning AC, Houwert RM, Verleisdonk EMM, et al. Associated thoracic injury in patients with a clavicle fracture: a retrospective analysis of 1461 
polytrauma patients. Eur J Trauma Emerg Surg. 2016;57:780-5.

12. Langenbach A, Pinther M, Krinner S, Grupp S, Ekkernkamp A, Hennig FF, et al. Surgical Stabilization of Costoclavicular Injuries - A Combination of Flail Chest Injuries and a Clavicula Fracture. Chirurgia. 2017;112:595-606.

13. Leinicke JA, Elmore L, Freeman BD, Colditz GA. Operative Management of Rib Fractures in the Setting of Flail Chest. Ann. Surg. 2013;258:914-21.

14. Grubmüller M, Kerschbaum M, Diepold E, Angerpointner K, Nerlich M, Ernstberger A. Severe thoracic trauma - still an independent predictor for death in multiple injured patients? Scand J Trauma Resusc Emerg Med. 2018;26:1-8.

15. Galvagno SM, Smith CE, Varon AJ, Hasenboehler EA, Sultan S, Shaefer G, et al. Pain management for blunt thoracic trauma: A joint practice management guideline from the Eastern Association for the Surgery of Trauma and Trauma Anesthesiology Society. J Trauma Acute Care Surg. 2016;81:93651.

16. Bonnevie T, Gravier F-E, Ducrocq A, Debeaumont D, Viacroze C, Cuvelier A, et al. Exercise testing in patients with diaphragm paresis. Respir Physiol Neurobiol. 2018;248:31-5.

17. Ramsook AH, Molgat-Seon Y, Schaeffer MR, Wilkie SS, Camp PG, Reid WD, et al. Effects of inspiratory muscle training on respiratory muscle electromyography and dyspnea during exercise in healthy men. J. Appl. Physiol. American Physiological Society Bethesda, MD; 2017;122:1267-75.

18. Ruchholtz S, Waydhas C, Ose C, Lewan U, Nast-Kolb D. Prehospital intubation in severe thoracic trauma without respiratory insufficiency: a matched-pair analysis based on the Trauma Registry of the German Trauma Society. J Trauma. 2002;52:879-86.

19. Haasper $C$, Junge $M$, Ernstberger $A, B$ rehme $H$, Hannawald L, Langer $C$, et al. The Abbreviated Injury Scale (AIS). Options and problems in application. Unfallchirurg. 2010;113:366-72.

20. Osler T, Baker SP, Long W. A modification of the injury severity score that both improves accuracy and simplifies scoring. J Trauma. 1997;43:922-6.

21. Baker SP, O'Neill B, Haddon W, Long WB. The injury severity score: a method for describing patients with multiple injuries and evaluating emergency care. J Trauma. 1974;14:187-96.

22. Vincent JL, Moreno R, Takala J, Willatts S, De Mendonça A, Bruining H, et al. The SOFA (Sepsisrelated Organ Failure Assessment) score to describe organ dysfunction/failure. On behalf of the Working Group on Sepsis-Related Problems of the European Society of Intensive Care Medicine. Intensive Care Med. 1996. pp. 707-10.

23. Bone RC, Balk RA, Cerra FB, Dellinger RP, Fein AM, Knaus WA, et al. Definitions for Sepsis and Organ Failure and Guidelines for the Use of Innovative Therapies in Sepsis. Chest. 1992;101:1644-55.

24. Lefering R, Huber-Wagner S, Nienaber U, Maegele M, Bouillon B. Update of the trauma risk adjustment model of the TraumaRegister DGU ${ }^{\text {TM: }}$ : the Revised Injury Severity Classification, version II. Crit Care. 2014;18:476.

25. Battle C, Hutchings $H$, Lovett S, Bouamra O, Jones S, Sen A, et al. Predicting outcomes after blunt chest wall trauma: development and external validation of a new prognostic model. Crit Care. 
2014;18:R98.

26. Banerjee M, Bouillon B, Shafizadeh S, Paffrath T, Lefering R, Wafaisade A, et al. Epidemiology of extremity injuries in multiple trauma patients. Injury. 2013;44:1015-21.

27. Schulz-Drost S, Oppel P, Grupp S, Krinner S, Langenbach A, Lefering R, et al. Bony injuries of the thoracic cage in multiple trauma. Unfallchirurg. 2015;119:1023-30.

28. Hildebrand F, Giannoudis PV, Griensven MV, Zelle B, Ulmer B, Krettek C, et al. Management of polytraumatized patients with associated blunt chest trauma: a comparison of two European countries. Injury. 2005;36:293-302.

29. Hill AB, Fleiszer DM, Brown RA. Chest trauma in a Canadian urban setting-implications for trauma research in Canada. J Trauma. 1991;31:971-3.

30. Bayer J, Lefering R, Reinhardt S, Kühle J, Südkamp NP, Hammer T, et al. Severity-dependent differences in early management of thoracic trauma in severely injured patients - Analysis based on the TraumaRegister DGU®. Scand J Trauma Resusc Emerg Med. 2017;25:10.

31. Lee RB, Bass SM, Morris JA, MacKenzie EJ. Three or more rib fractures as an indicator for transfer to a Level I trauma center: a population-based study. J Trauma. 1990;30:689-94.

32. Minei JP, Fabian TC, Guffey DM, Newgard CD, Bulger EM, Brasel KJ, et al. Increased trauma center volume is associated with improved survival after severe injury: results of a Resuscitation Outcomes Consortium study. Ann. Surg. 2014;260:456-65.

33. Briese T, Theisen C, Schliemann B, Raschke MJ, Lefering R, Weimann A. Shoulder injuries in polytraumatized patients: an analysis of the TraumaRegister DGU®. Eur J Trauma Emerg Surg. 2020;38:580-10.

34. Huber S, Biberthaler P, Delhey $\mathrm{P}$, Trentzsch $\mathrm{H}$, Winter $\mathrm{H}$, van Griensven $\mathrm{M}$, et al. Predictors of poor outcomes after significant chest trauma in multiply injured patients: a retrospective analysis from the German Trauma Registry (Trauma Register DGU®). Scand J Trauma Resusc Emerg Med. 2014;22:52-9.

35. Krinner S, Hennig FF, Ekkernkamp A, Schulz-Drost S. Injuries of the posterior and lateral chest wallimportance of an additional clavicular fracture. Unfallchirurg. 2018;121:615-623(2018):1-9.

36. RiehI J, Athans B, Munro M, Langford J, Kupiszewski S, Haidukewych G, et al. Minimally displaced clavicle fracture after high-energy injury: Are they likely to displace? Can J Surg. 2014;57:169-74.

37. Stahl D, Ellington M, Brennan K, Brennan M. Association of Ipsilateral Rib Fractures With Displacement of Midshaft Clavicle Fractures. J Orthop Trauma. 2017;31:225-8.

38. Ware LB, Matthay MA. The acute respiratory distress syndrome. N. Engl. J. Med. 2000;342:1334-49.

39. Ashbaugh DG, Bigelow DB, Petty TL, Levine BE. Acute respiratory distress in adults. Lancet. 1967;2:319-23.

40. Fröhlich $M$, Lefering R, Probst $C$, Paffrath $T$, Schneider MM, Maegele $M$, et al. Epidemiology and risk factors of multiple-organ failure after multiple trauma: an analysis of 31,154 patients from the TraumaRegister DGU. J Trauma Acute Care Surg. 2014;76:921-8. 
41. Minei JP, Cuschieri J, Sperry J, Moore EE, West MA, Harbrecht BG, et al. The changing pattern and implications of multiple organ failure after blunt injury with hemorrhagic shock. Crit. Care Med. 2012;40:1129-35.

42. Schuurmans J, Goslings JC, Schepers T. Operative management versus non-operative management of rib fractures in flail chest injuries: a systematic review. Eur J Trauma Emerg Surg. 2017;43:163-8.

43. Leroux T, Wasserstein D, Henry P, Khoshbin A, Dwyer T, Ogilvie-Harris D, et al. Rate of and Risk Factors for Reoperations After Open Reduction and Internal Fixation of Midshaft Clavicle Fractures: A Population-Based Study in Ontario, Canada. J Bone Joint Surg Am. 2014;96:1119-25.

44. Rehn $\mathrm{C}-\mathrm{H}$, Kirkegaard M, Viberg B, Larsen MS. Operative versus nonoperative treatment of displaced midshaft clavicle fractures in adults: a systematic review. Eur J Orthop Surg Traumatol. 2014;24:1047-53.

45. Pape HC, Halvachizadeh S, Leenen L, Velmahos GD, Buckley R, Giannoudis PV. Timing of major fracture care in polytrauma patients - An update on principles, parameters and strategies for 2020. Injury. 2019;50:1656-70.

46. Hager S, Eberbach H, Lefering R, Hammer TO, Kubosch D, Jäger C, et al. Possible advantages of early stabilization of spinal fractures in multiply injured patients with leading thoracic trauma - analysis based on the TraumaRegister DGUß. Scand J Trauma Resusc Emerg Med. 2020;28:42-11.

47. Lefering R, Paffrath T. Reality of care based on the data from the Trauma Registry of the German Society of Trauma Surgery. Unfallchirurg. 2012;115:30-2.

\section{Figures}




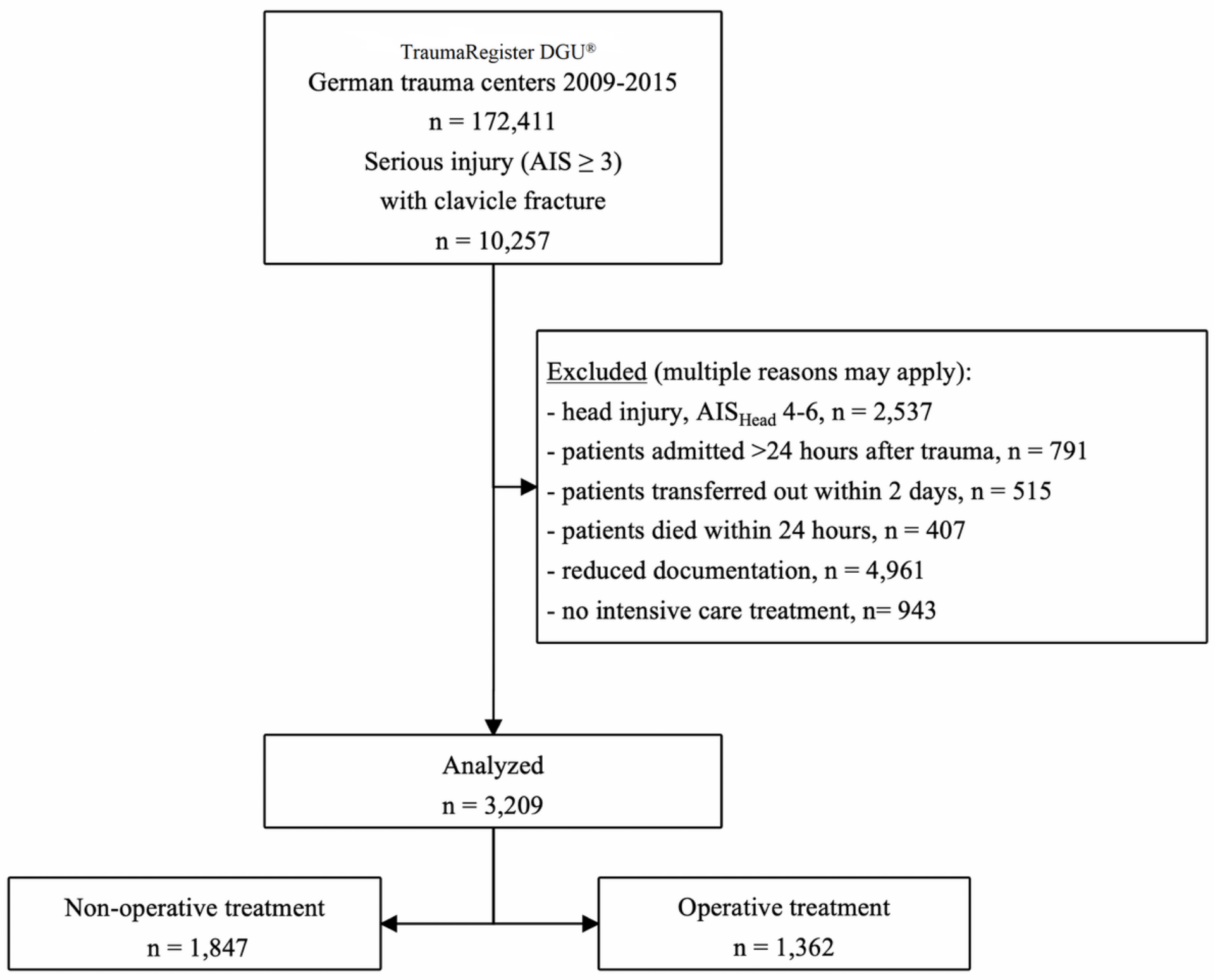

Figure 1

Flowchart showing inclusion and exclusion of patients for this study 


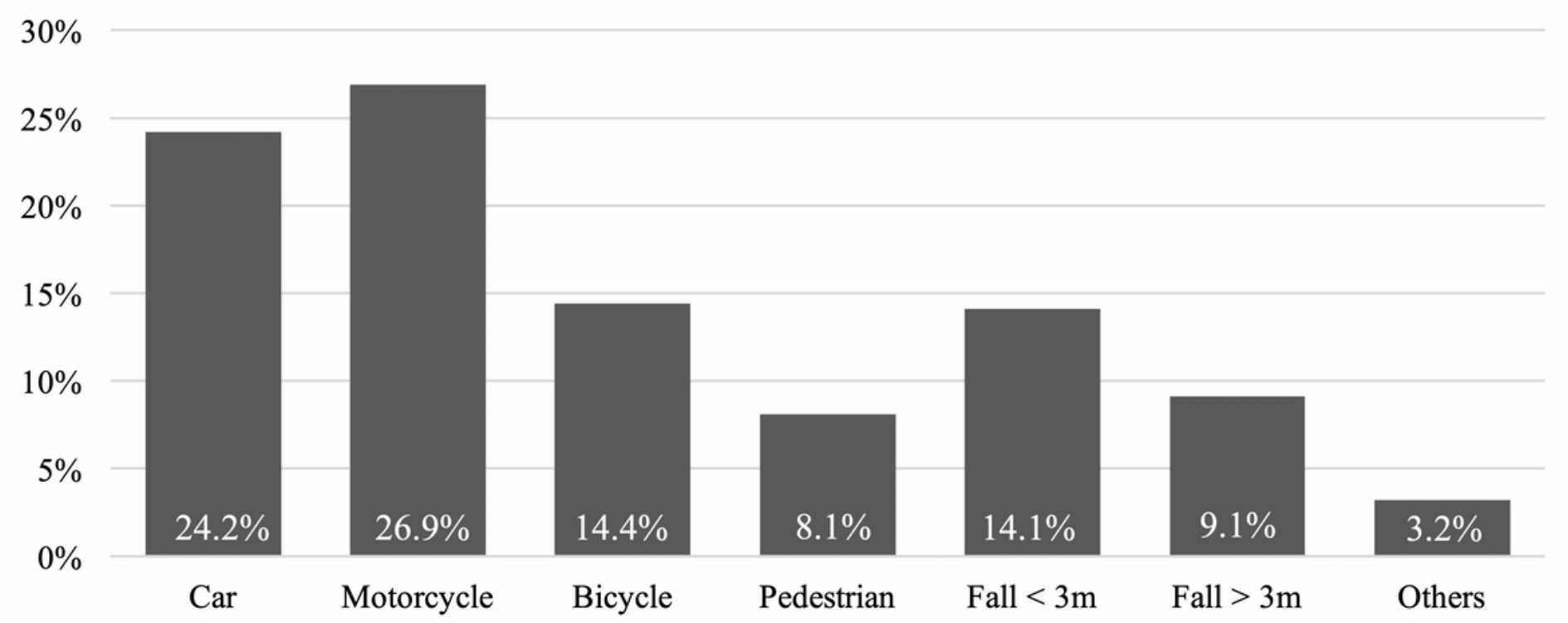

Figure 2

Trauma mechanism

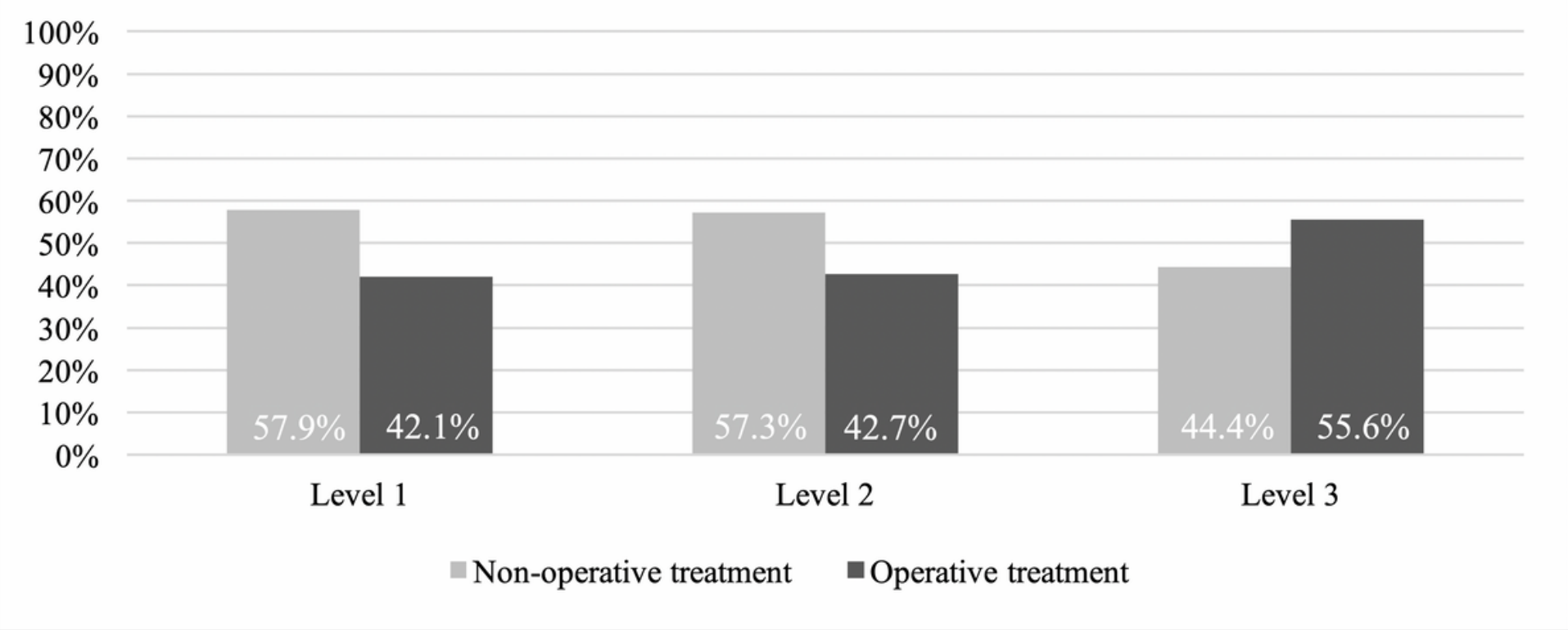

\section{Figure 3}

Treatment modality according to level of trauma center 


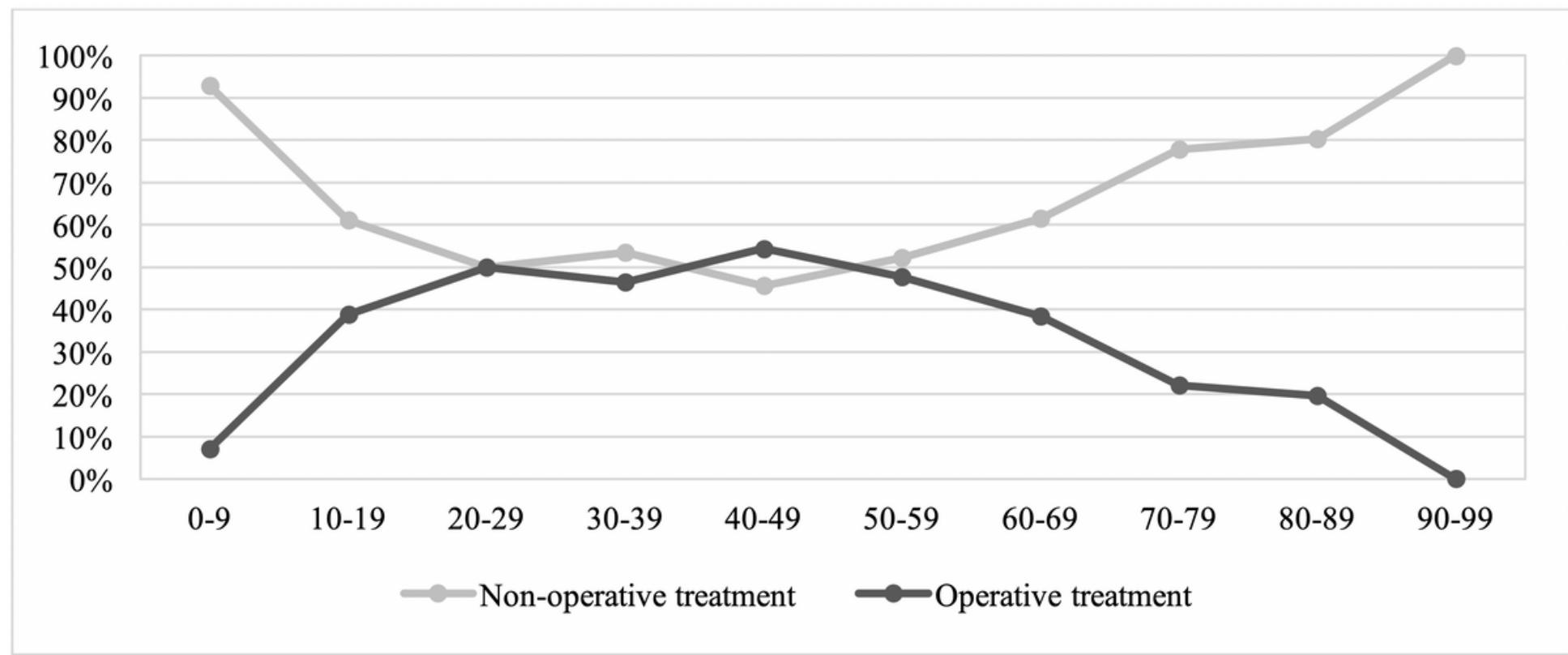

\section{Figure 4}

Treatment modality according to patient age 